\title{
Uma experiência com o binômio [Design thinking + pensamento computacional] para o letramento digital do público feminino através do desenvolvimento de games
}

\author{
Raquel Moreira Machado Fernandes ${ }^{1,2}$, Ana Paula Cavadas Rodrigues ${ }^{3}$, \\ Claudia Lage Rebello da Motta ${ }^{1,3}$, Carla Verônica Machado Marques ${ }^{3}$, Carlo \\ Emmanoel Tolla de Oliveira ${ }^{3}$ \\ ${ }^{1}$ Programa de Pós Graduação em Informática da Universidade Federal do Rio de \\ Janeiro \\ ${ }^{2}$ Universidade Federal Fluminense \\ ${ }^{3}$ Instituto Tércio Pacitti de Aplicações e Pesquisas Computacionais da Universidade \\ Federal do Rio de Janeiro

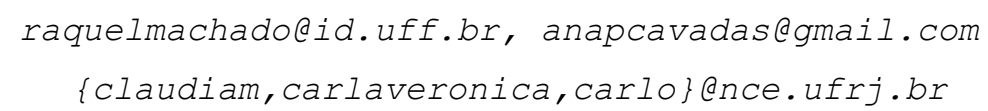

Abstract. This paper aims to report a successful experience about the use of design thinking and computational thinking for creative learning of computation by elementary school girls in a public school in Rio de Janeiro, in a conflagrated area. The experience integrated an extension project to promote digital literacy for female audiences using educational tools and games for teaching programming. Through design thinking, students manipulated objects and developed creatively, using computational thinking to solve a real problem in the community in which they live. We suggest that the binomial of [design thinking + computational thinking] may contribute to attract and stimulate youngs in computation, enabling new skills in students.

Resumo. Este artigo tem como objetivo relatar uma experiência bem-sucedida sobre o uso do design thinking e do pensamento computacional para o aprendizado criativo da computação por meninas do ensino fundamental de uma escola pública do Rio de Janeiro, em uma área conflituosa. A experiência integrou um projeto de extensão para promover a alfabetização digital para o público feminino com o uso de ferramentas e jogos educacionais para o ensino da programação. Através do design thinking, as alunas manipularam objetos e se desenvolveram criativamente, usando o pensamento computacional para resolver um problema real na comunidade em que vivem. Sugerimos que o binômio [design thinking + pensamento computacional] pode contribuir para atrair e estimular jovens na computação, habilitando novas competências.

\section{Introdução}

Atualmente a educação em Informática na educação básica não é disciplina obrigatória no Brasil. De acordo com Lacerda (2012), desde 1993 existem projetos de lei para a inclusão da informática na educação escolar; no entanto, a efetiva implantação em todo o território nacional ainda não ocorreu. Apesar de alguns municípios ofertarem a Informática na educação básica, as iniciativas de inclusão digital e apropriação 
tecnológica voltadas para crianças e adolescentes ainda são bastante pontuais ou realizadas através de projetos de extensão das universidades públicas.

Os desafios para implantação devem-se, principalmente, à necessidade de mais apoio governamental e de novas políticas públicas para aquisição de equipamentos, formação de profissionais docentes capazes de ensinar considerando as especificidades da atual sociedade da informação digital e também de profissionais para realizar manutenção dos equipamentos disponibilizados às comunidades escolares. Apesar de tais desafios, os indicadores ${ }^{1}$ mais recentes divulgados pelo Centro Regional de Estudos para o Desenvolvimento da Sociedade da Informação (Cetic.br) apontam que hoje 99\% das escolas localizadas em áreas urbanas possuem computadores e $98 \%$ têm acesso à Internet. Contudo, de acordo com a mesma pesquisa, apenas $48 \%$ das escolas relataram usar o laboratório de informática em atividades educacionais.

A privação do contato com a informática na educação básica pode ser um fator de desigualdade na ciência e no mercado brasileiro. Silva (2018) apresenta um caso em que ex-alunos do ensino médio relataram dificuldades ao ingressarem no nível superior devido à falta de conhecimento do mundo digital. Tal privação também poderia causar dificuldade de ingressar no mercado de trabalho, sobretudo nas carreiras em tecnologia. A Associação Brasileira das Empresas de Tecnologia da Informação e Comunicação (Brasscom) identificou ${ }^{2}$ um excesso de vagas e ausência de mão de obra qualificada no mercado de Tecnologia do Brasil. Além da falta de contato com a informática na educação básica, também identificamos outro fator que causa desigualdade na ciência e no mercado de trabalho brasileiro: a insuficiente falta de estímulo à diversidade de gênero nas áreas conhecidas como STEAM (Ciências, Tecnologia, Engenharia, Artes e Matemática). Apesar de o número de estudantes formados em Ciência da Computação e Engenharia ter alcançado um aumento significativo, o grupo feminino ainda está em um ponto baixo. De acordo com o Relatório Gender and education for all: the leap to equality, da Organização das Nações Unidas para a Educação (UNESCO), algumas motivações podem ser a desigualdade de gênero, a educação sexista, estereótipos de gênero no ambiente escolar, implicações decorrentes da forma pela qual o poder é compartilhado dentro das famílias, entre outras.

$\mathrm{Na}$ contramão deste cenário, existem muitas iniciativas no Brasil com o objetivo de redefinir a experiência escolar, de modo que as oportunidades de aprendizagem sejam tanto um direito, quanto um objetivo, prestando-se a promover o empoderamento feminino, fortalecer o engajamento e buscar uma paridade de gêneros, ajudando meninas e mulheres a se sentirem motivadas a explorar as áreas de tecnologia, programação e empreendedorismo.

\section{Trabalhos relacionados}

O empoderamento feminino em Tecnologia e Engenharia e o incentivo à STEAM têm sido um tema relevante no Brasil e no mundo.

Maciel et al. (2016) apresentam o Programa Meninas Digitais, que tem como objetivo divulgar a área de Computação para despertar o interesse de meninas do ensino fundamental e do ensino médio. Embora a perspectiva dos autores seja semelhante à abordagem proposta, nosso trabalho difere ao utilizar uma abordagem focada no ensino

$1 \mathrm{https} / / /$ cetic.br/pesquisa/educacao/indicadores

2https://oglobo.globo.com/economia/emprego/mercado-de-tecnologia-tem-deficit-de-24-milprofissionais-por-ano-24170633 
de programação em vez de atividades com temáticas abrangendo diversas áreas da informática. Assim como Resnick (2013), acreditamos que programar é o caminho para a fluência tecnológica; a programação não ajuda as crianças apenas em termos práticos, mas também ajuda a organizar idéias e enxergar o mundo de maneiras diferentes, além de permitir uma participação social efetivamente ativa. Assumimos que criar um programa é como contar histórias através de possibilidades. É apresentar eventos, descrever objetos, atribuir variáveis e sentidos; é manipular linguagens. Abstrair sobre as condições. Assim como na expressão, encadeamento e sequência lógica são competências necessárias; é preciso criatividade, fluência, compreensão de códigos e símbolos, dimensionamento de espaço, tempo e possibilidades. São necessários verbos de ação. Demanda organização e consciência estrutural; portanto, segundo Machado et al. (2016), é uma atividade capaz de auxiliar no desenvolvimento cognitivo.

OEmili@s - Armação em Bits é uma iniciativa da Universidade Tecnológica Federal do Paraná, com o objetivo de reconhecer a voz das mulheres na área de computação e atrair mais mulheres na área. As ações deste projeto envolvem a oferta de oficinas em áreas como Interação Humano-Computador, Banco de Dados e Web Design.

Outras iniciativas no Brasil são \#include.gurias no sul do país e Cunhantã Digital, com foco em mulheres na região amazônica. A representação das mulheres em Engenharia e Tecnologia da Informação, contudo, é uma questão mundial. Em países como a Nova Zelândia, iniciativas como o Shadow It in (Hunter et al., 2017) buscam aproximar estudantes de mulheres que trabalham profissionalmente na área de TI. Essa aproximação ainda não é privilegiada em nossa abordagem, pois depende de maior maturação do projeto.

Nos Estados Unidos, alguns programas depois da escola, como o descrito por Werner et al. (2005), visam desenvolver a fluência em tecnologia da informação, ensinando meninas do ensino médio a desenvolverem jogos de computador. Nesse caso, nossa abordagem difere, pois oferece, além do treinamento em programação de jogos, treinamento na aquisição de habilidades e experimentação de metodologias ágeis e Design Thinking, buscando prepará-las para as atividades do quotidiano, como em uma equipe de desenvolvimento real e moderna.

\section{O projeto SuPyGirls}

O projeto SuPyGirls ${ }^{3}$ visa valorizar e capacitar mulheres na área tecnológica por meio de software livre e estratégias neurocomputacionais para a criação de jogos e superação de desafios. Contextualizado na prática relevante da Universidade Federal do Rio de Janeiro na aplicação de políticas públicas que contribuem para a sociedade, o projeto ${ }^{4}$ envolve estudantes de diferentes níveis de ensino em processos de treinamento baseados no aprendizado prático e colaborativo. Com isso, esperamos motivar as meninas da educação básica a se formarem em Ciência da Computação e modificarem suas perspectivas de vida, usando a tecnologia como fator gerador de empoderamento e autonomia. Para tanto, estudantes de mestrado e graduação atuam como monitores do programa, ensinando meninas do ensino médio e fundamental.

A pesquisa apresentada foi realizada com 10 meninas que participaram voluntariamente do projeto no período de agosto a dezembro de 2019. A faixa etária

3 supygirls.activufrj.nce.ufrj.br

4 https://web.facebook.com/Projeto-SupyGirls-2062797764002029/ 
varia de de 13 a 15 anos e as estudantes cursavam o sexto ano do ensino fundamental na Escola Municipal Jornalista e Escritor Daniel Piza. A escola está localizada na região da Pedreira, localizada entre os bairros Acari e Costa Barros, que de acordo com os dados ${ }^{5}$ mais recentes do Instituto Brasileiro de Geografia e Estatística (IBGE), ocuparam respectivamente o $124^{\circ}$ e $125^{\circ}$ lugar das 126 regiões analisadas na cidade do Rio de Janeiro.

Com apenas 10 computadores e acesso de baixa qualidade à Internet, esta é uma das escolas cujos professores não usam o laboratório de informática com frequência. A realização do projeto nesta escola, portanto, buscou aproximar as estudantes da tecnologia, incentivando-as a buscar uma carreira profissional, a fim de afastá-las da violência, do tráfico e da gravidez na adolescência, de modo a apresentar novas possibilidades e perspectivas de vida para uma amostra em situação de vulnerabilidades socioeconômicas.

Uma entrevista não estruturada realizada no início do projeto revelou que entre 6 estudantes que manifestaram interesse em cursar o ensino superior, nenhuma indicou como desejada uma carreira na área de tecnologia. Em um teste prático realizado na primeira aula, constatou-se que as estudantes não possuíam conhecimentos básicos em Informática.

\section{Fundamentação teórica}

Esta pesquisa tem como fundamentação teórica conceitos e pesquisas advindos da Neuropedagogia Computacional, uma ciência transdisciplinar que apresenta um modelo neurocientífico-pedagógico de Educação alicerçado em jogos digitais. A perspectiva adotada fundamenta-se em Marques et al. (2019), que apresentam a utilização da metodologia Marques-Oliveira como estratégia pedagógica, de modo a promover a alfabetização e a fluência digital, mediando a metacognição através de técnicas como o Fio Condutor Microgenético, numa perspectiva construcionista onde os estudantes têm a oportunidade de construir e programar jogos, com um processo de concepção baseado em um modelo de pesquisa científica, ativando e desenvolvendo funções cognitivas. A metodologia Marques-Oliveira é, portanto, uma metodologia para concepção de games inteligentes. Por meio dela, é possível realizar atividades de concepção de jogos digitais para realização de capturas cognitivas e também habilitar competências lógicolinguísticas de forma sistêmica durante a atividade de concepção do game.

A proposta contemplada apresenta o Design Thinking e o Pensamento computacional como um binômio de sucesso para o letramento digital e para o aprendizado criativo da programação de jogos.

O Design Thinking é uma estrutura centrada no ser humano para a inovação. Ele fornece uma abordagem baseada em solução para resolver problemas em cinco estágios, sendo eles: Empatia, Definição do problema, Ideação, Prototipação e Teste, no modelo proposto pelo Instituto de Design Hasso-Plattner da Universidade de Stanford.

O Pensamento Computacional (Wing, 2008) é uma abordagem para resolução de problemas através de conceitos fundamentais da Ciência da Computação. Os conceitos principais são abstração, decomposição, reconhecimento de padrões e design de 
algoritmos. Esses conceitos auxiliam na solução de um grande problema a partir da divisão do todo em partes menores.

\section{Metodologia e Proposta}

Esta pesquisa adotou o Construcionismo como uma perspectiva epistemológica, seguindo com uma perspectiva epistemológica descritiva de uma metodologia experimental com abordagem qualitativa. Como procedimento metodológico, privilegiamos a observação participante.

Para o desenvolvimento da proposta, assumimos as seguintes hipóteses:

1) Com base em Fernandes (2019), o pensamento narratológico funciona como epísteme da linguagem código lógico-sistêmica (Seminério, 1987). Sendo o pensamento narratológico possibilitado pela criatividade oportunizada pelo processamento do imaginário, segundo o modelo de entrada - processamento - saída, onde têm-se: imaginário - criatividade - produto criativo, o pensamento computacional relaciona-se à criatividade em um nível de dependência, pois para realizar operações de abstração, decomposição, reconhecimento de padrões e design é necessário ter criatividade para seleção e organização dos significantes e significados. Desse modo, o Design Thinking possibilita a criação de um espaço de narração sobre uma persona e incita a criatividade considerando uma ecologia holística que envolve problemas, soluções e pessoas.

2) A necessidade de criatividade para configuração desse espaço de narração suscita diferentes operações cognitivas, capazes de habilitar novas competências nas aprendizes. O Design Thinking, portanto, pode ser utilizado para desenvolver habilidades de pensamento computacional, promovendo, também, o desenvolvimento de um sujeito epistêmico como resultado de uma construção a partir da criação e da ação do próprio sujeito.

Como parte do trabalho, elaboramos a Tabela 1 e relacionamos as etapas do Design Thinking e do Pensamento Computacional às etapas da STEAM como uma proposta de trilha de aprendizagem que pode auxiliar o desenvolvimento da fluência em Computação.

Tabela 1. Correlação de etapas e processos cognitivos

\begin{tabular}{|c|c|c|}
\hline Design Thinking & Pensamento Computacional & Etapas STEAM \\
\hline Empatia & Decomposição & Investigar \\
\hline Definição do problema & Reconhecimento de padrões & Descobrir \\
\hline Ideação & Abstração & Refletir \\
& & Conectar \\
\hline Prototipação & Abstração & Conectar \\
& Design de Algoritmo & Criar \\
\hline Teste & Fluência em Tecnologia da Informação & Conectar \\
& & Refletir \\
\hline
\end{tabular}


Através do mapa da empatia, recurso do Design Thinking, é possível praticar operações de decomposição, separando os elementos constitutivos do perfil de uma pessoa e buscando entender cada aspecto isoladamente. Neste mapa, é comum a presença de perguntas como "O que a pessoa ouve?" e "O que a pessoa faz?". A pergunta "O que a pessoa pensa e sente?" aparece como um elemento central e dentro da cabeça do template, o que evidencia a necessidade de decompor e compreender isoladamente as diferenças entre os fenômenos observáveis, que se manifestam externamente, e pensamentos e sentimentos, processos internos do indivíduo.

O reconhecimento de um padrão ou de uma sequência prejudicial é essencial para a identificação e definição de um problema. Ao perceber uma situação que acontece com frequência ou uma situação padrão em um determinado contexto social, os alunos estão identificando um problema e exercitando o reconhecimento de padrões. A identificação de casos frequentes de violência contra a mulher, em um determinado padrão de ocorrência, é um exemplo de como pode-se identificar e definir um problema.

No estágio de ideação, é necessário pensar em possíveis soluções. Isso envolve a busca pela abrangência, de modo com que uma solução funcione em muitas situações semelhantes. Nesse caso, há um grande estímulo à abstração. Além disso, a abstração também é utilizada para avaliar um problema e extrair uma representação levando em consideração um aspecto para propor a solução. No exemplo dado anteriormente, vemos que existem diversos tipos de violência. Contudo, na tarefa de ideação, seria necessário optar por um dos tipos existentes e propor uma solução que pudesse abranger diferentes contextos em que ele pudesse ocorrer.

$\mathrm{Na}$ fase de prototipagem, é necessário criar modelos representativos. Nesse caso, é possível exercer a abstração e também projetar algoritmos, dada a necessidade de criar fluxos de dinâmica e solução.

Finalmente, na etapa de teste, é possível desenvolver, nesta proposta, habilidades de programação que podem resultar em fluência digital. Além disso, a utilização do produto com outros estudantes pode auxiliar a promover o diálogo, a socialização, a disseminação do conhecimento, o reconhecimento das ações desenvolvidas, bem como garantir valor e função social aos produtos desenvolvidos, de modo que eles possam circular pela comunidade escolar e/ou local, demonstrando aos estudantes a utilidade prática dos conhecimentos adquiridos.

Para materialização da proposta, foi necessário adaptar o Design Thinking a uma metodologia focada no design e desenvolvimento de jogos. Para esse fim, usamos uma abordagem aqui denominada de game design thinking, onde, além dos recursos tradicionais utilizados, como mapa de empatia e mapa de personas, desenvolvemos recursos para criar mecânica, dinâmica e estética em uma adaptação da metodologia Marques-Oliveira (Marques et al., 2019). Desse modo, novos templates de design foram criados.

Durante a execução dos workshops, as estudantes podiam realizar pesquisas na internet, de modo a captar ideias e povoar o imaginário. As atividades de pesquisa foram importantes para promover o letramento digital, pois as estudantes puderam conhecer conceitos de Informática básica como Desktop, Browser e Software, e, em seguida, verificar seu funcionamento de forma prática. As pesquisas realizadas envolveram temas como "Mulheres na Computação" e "Objetos inventados por mulheres". 
A Figura 1 contém registros de um processo criativo realizado pelas estudantes.
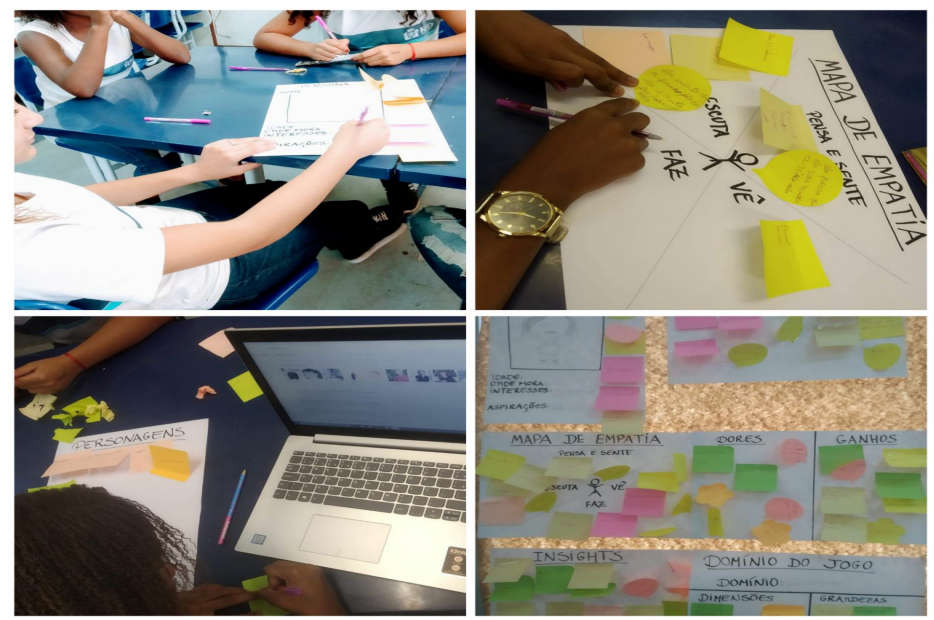

Figura 1. Processo criativo com Design Thinking

A disponibilização de materiais como cartolinas, canetas e post-its coloridos também foi um fator de motivação e de estimulação criativa na perspectiva da Lifelong Kindergarten (Resnick, 2017), abordagem que busca continuamente desenvolver a criatividade de forma divertida, criativa, leve e colaborativa, como no jardim de infância.

\section{Dinâmica de trabalho}

Para otimizar o tempo de execução do trabalho, uma vez que o projeto ocorria apenas uma vez por semana antes das aulas regulares, optamos pela utilização de metodologias ágeis. Trabalhando em uma equipe Scrum, foi possível explicar as etapas da engenharia de software, ensinar a linguagem de programação Python e desenvolver um jogo básico em pouco tempo.

No início do projeto, as estudantes participaram de palestras sobre empoderamento feminino e sobre mulheres importantes da história. Além disso, foram realizadas atividades com o gênero autorretrato com produção de textos e imagens, a fim de trabalhar questões de percepção, identidade e consciência corporal. Em seguida, foi necessário promover o letramento digital, uma vez que as participantes não possuíam conhecimentos de informática. Após essa etapa, realizamos os workshops de Design Thinking e somente após a concepção de todo o jogo, passamos às aulas de programação e construção do jogo.

Nas atividades práticas de programação, utilizamos a plataforma SuperPython ${ }^{6}$, desenvolvida por pesquisadores da Universidade Federal do Rio de Janeiro especialmente para este projeto. A plataforma contém um ambiente divertido para atividades básicas de programação na linguagem Python. SuperPython funciona no navegador Firefox e utiliza imagens da Internet através do Plugin Imgur. As imagens utilizadas são devidamente referenciadas de acordo com suas licenças. Também damos às alunas a oportunidade de criarem suas próprias imagens usando software livre de edição de imagens ou sites como o Canva.com. É possível também fazer o upload de desenhos produzidos pelas estudantes. 
Buscamos também fornecer uma apresentação visual agradável dos conteúdos e atividades fornecidas, de modo a minimizar o distanciamento das estudantes com a Tecnologia e com as temáticas abordadas. Para tanto, os manuais e apresentações fornecidos foram elaborados com cores e personagens que buscassem gerar identificação e fortalecer a autoestima. Foram fornecidos guidelines que mostravam o passo a passo a ser seguido para a realização de cada atividade prática, mas cada estudante seguiu de maneira diferente, de acordo com suas escolhas e sua criatividade. A personalização é uma parte importante da abordagem usada. Apesar de ter um tema de jogo comum, cada estudante desenvolveu sua própria versão do código do jogo. Em resumo, a dinâmica do trabalho privilegiou etapas dedicadas aos seguintes aspectos: 1) Consciência coletiva para o empoderamento feminino 2) Letramento digital 3) Criatividade e Design Thinking e 4) Fluência digital e empoderamento tecnológico feminino.

\section{Avaliação e Resultados}

Em relação à avaliação, é importante enfatizar que a observação sistemática do comportamento dos alunos envolvidos é capaz de revelar, através do processo de avaliação implícita, evidências de desenvolvimento cognitivo e melhorias em vários aspectos da aprendizagem. Portanto, consideramos a participação e o desenvolvimento dos estudantes em relação às categorias de domínio cognitivo aplicadas por Bloom (2015) em uma perspectiva qualitativa. Como avaliação explícita, verificamos o desempenho ao realizar atividades práticas, verificando se as estudantes realizavam as atividades de maneira criativa com base nas métricas de Torrance (1976). Também consistiu material de avaliação os templates de Design Thinking preenchidos e a narrativa elaborada para o jogo.

Quanto ao tema do jogo, ele foi selecionado pelas próprias participantes, que, após as primeiras atividades do projeto, identificaram um problema na comunidade em que vivem: a população não conhece mulheres importantes na história, nem suas ações e invenções. Ao descobrirem que muitos objetos usados diariamente foram feitos por mulheres, as estudantes buscaram disseminar esse conhecimento como uma forma de resgatar o protagonismo feminino na sociedade. Para tanto, dentro da proposta de utilização de jogos junto ao público feminino contemplada no Projeto SuPyGirls, as estudantes escolheram criar um jogo que difundisse o protagonismo feminino, com foco nos objetos criados pelas mulheres. Assim, uma história para o jogo foi elaborada, retratada em diferentes fases com níveis de desafios, o que possibilitou uma avaliação multidimensional.

Para a narrativa do jogo, foi feita uma avaliação baseada no paradigma e no sintagma. Sobre o sintagma, verificou-se os aspectos de causalidade, agentividade, organização temporal, contingência e integração. Em relação à agentividade, verificamos agentes integrados e uma organização temporal com sequências organizadas. Em relação à contingência, os fatos poderiam ser mais explorados. Em relação à integração, as imagens e as histórias produzidas tinham temática em comum, porém intervenções futuras deverão ser realizadas para promover uma melhora nos aspectos sintagmáticos, uma vez que as cenas produzidas tinham menos relações entre si e mais relações com a temática. Já, na análise paradigmática, observamos um paradigma intermediário com tendência ao socializado, o que demonstra uma evolução das estudantes na relação pensamento-linguagem-conhecimento. 
O objetivo de promover a fluência digital foi alcançado, uma vez que as estudantes passaram a conhecer o computador, seu funcionamento e puderam utilizá-lo para realizar as atividades, apropriando-se do conhecimento adquirido para desenvolver o seu próprio produto criativo.

Os resultados das análises qualitativas realizadas acerca dos aspectos de paradigma e sintagma são importantes no campo da linguagem e podem ajudar o professor a compreender as dificuldades da amostra. Também é possível avaliar o conhecimento de outras disciplinas de maneira interdisciplinar. Nesse caso, as disciplinas relacionadas foram História e Ciências, uma vez que as estudantes também destacaram importantes descobertas científicas feitas por mulheres.

O código e o jogo produzidos de forma criativa pelas estudantes são um excelente produto; no entanto, o melhor resultado é o sucesso da experiência, que proporcionou às alunas o exercício da criatividade, do pensamento computacional, o aprendizado da lógica de programação e o conhecimento da linguagem Python. A aprendizagem criativa da programação é uma possibilidade promissora para o futuro dessas estudantes.

Em relação à execução da proposta, as estudantes apresentaram duas dificuldades: a dificuldade de compreensão da sintaxe da linguagem de programação e dificuldade elaboração da narrativa para o jogo. Com isso, enfatizamos a perspectiva apresentada por Machado et al. (2016), onde leitura, escrita e programação são atividades essenciais para a era da informação. Devem, portanto, ser estimuladas, praticadas e desenvolvidas de forma conjunta, interdisciplinar e multidimensional, de modo que as estudantes sejam protagonistas no processo de aprendizagem através de tarefas que possibilitem investigar, descobrir, conectar, criar e refletir.

Em relação ao engajamento das meninas em STEAM, destacamos que o projeto impulsionou o envolvimento das estudantes da educação básica com a comunidade científica. As participantes apresentaram os resultados de seu trabalho na Semana Acadêmica da Universidade Federal do Rio de Janeiro e pretendem participar de mais eventos na área de programação, desenvolvimento e tecnologias.

\section{Conclusão e Trabalhos futuros}

Com a realização desta pesquisa, concluiu-se, portanto, que o binômio Design Thinking + Pensamento Computacional é uma abordagem promissora que pode ser utilizada em diferentes situações e contextos de aprendizagem, podendo auxiliar uma diversidade de sujeitos na elaboração e execução de projetos criativos e colaborativos que aproximem a escola do contexto sócio-histórico-econômico atual, usando a tecnologia como agente de empoderamento e minimização de desigualdades.

Como trabalhos futuros, pretendemos realizar um estudo longitudinal para verificar ao longo do tempo o real envolvimento das participantes do projeto nas áreas de Ciência da Computação. Também pretendemos estender o projeto a mais meninas e mais escolas, buscando parcerias para melhorar a infraestrutura tecnológica disponibilizada.

Também pretendemos desenvolver um modelo de avaliação multidimensional capaz de abranger todos os aspectos presentes na Tabela 1. Desta forma, pretendemos contribuir para a expansão da Ciência da Computação, dando às mulheres a oportunidade de serem cada vez mais protagonistas na sociedade da informação digital. 


\section{Referências}

Bloom's taxonomy of cognitive learning objectives. J Med Libr Assoc. 2015, Jul; 103(3): 152-153. Doi 10.3163/1536-5050.103.3.010

Fernandes, Raquel M. M. (2019). O desenvolvimento da competência narrativa com o usos de modelos neurocientífico-pedagógicos apoiados pela tecnologia. 2019. Dissertação (Mestrado em Informática) - Universidade Federal do Rio de Janeiro.

Hunter, A.; Boersen, R. (2017) Out from the shadows: Encouraging Girls in New Zealand into IT careers. Proceedings of the 2017 ACM ITICSE.

Lacerda, M. (2012) Informática como disciplina obrigatória na Educação Básica. Anais do IX Encontro virtual de documentação em software livre e VI congresso internacional de linguagem e tecnologia online. Volume 1, Numero 1.

Machado, R.M.; Cavadas, A.P.C.; Fernandes, L.F.A.; Motta, C.L.R. (2016) Ler, escrever e programar: atividades essenciais para o desenvolvimento cognitivo na era da informação. Nuevas Ideas en Informatica Educativa, Volumen 12, TISE.

Maciel, C.; Bim, S.A. (2016) Programa Meninas Digitais - Ações para divulgar a computação para meninas do ensino médio. Proceedings of Computer on the Beach.

Marques, C.V.M.; Oliveira, C.E.T.; Fernandes, R.M.M. Metodologia neurocientíficapedagógica aplicada à concepção de jogos para ativação das funções cognitivas de estudantes da educação básica. Jornada de Atualização em Informática na Educação. CBIE, 2019.

Resnick, M. (2013). Let's teach kids to code. TED Talks.

Resnick, M. 2017. Lifelong Kindergarten: Cultivate Creativity Through Projects, Passion, Peers, and Play. Cambridge, MA: MIT Press; 2017 ISBN-10: 0262037297

Seminério, F. (1987) Elaboração Dirigida : um caminho para desenvolvimento metaprocessual da cognição humana. Rio de Janeiro: Instituto Superior de Estudos e Pesquisas Psicossociais. Cadernos do ISOP, no 10, Rio de Janeiro, Ed. FGV.

Silva, V. L. (2018) "O uso da tecnologia na Educação básica” In: Anais do V Congresso Nacional de Educação (CONEDU), V. 1, ISSN 2358-8829, Brasil.

Torrance, E. P. Criatividade: medidas, testes e avaliações. São Paulo, IBRASA, 1976

UNESCO (2003) Gender and education for all: the leap to equality.

Werner, L.; Campe, S. Middle school girls + games programming = information technology fluency. (2005) Proceedings of the 6th Conference On Information Technology Education.

Wing, J. M. Computational thinking and thinking about computing. Philos Trans A Math Phys Eng Sci. 2008 Oct 28; 366(1881): 3717-3725. 